International Journal of Advanced Trends in Computer Science and Engineering

Available Online at http://www.warse.org/IJATCSE/static/pdf/file/ijatcse35822019.pdf

https://doi.org/10.30534/ijatcse/2019/35822019

\title{
Development of a Cost-Efficient Waste bin Management System with Mobile Monitoring and Tracking
}

\author{
Aaron Don M. Africa, Charleston Franklin C. Uy \\ Department of Electronics and Communications Engineering \\ De La Salle University, Manila \\ 2401 Taft Ave., Malate, Manila 1004, \\ Philippines, aaron.africa@dlsu.edu.ph
}

\begin{abstract}
The Internet of Things, commonly known as IOT, is an ever-evolving technology which gives solutions that makes each aspect of everyday human life easier. Creating a smart waste management is one implementation that improves the sanitation and collection of waste. This paper aims in developing a waste management system that is cost-efficient and providing a mobile application to monitor and track the waste level. By making use of inexpensive sensors, microprocessors, the group was able to create a cheaper waste management system. Using firebase database and android studio, the group was able to create a mobile application that provide a graphical user interface (GUI) which serves as a visual presentation of the waste level as well as provide a notification when the waste reaches a certain amount of level. The main advantage of the prototype is its deployment since building it is not expensive and therefore able to be mass produced at a low cost.
\end{abstract}

Key words : Cost-efficient, IOT Device, Mobile Application, Waste Bin Management.

\section{INTRODUCTION}

In this information age, there are numerous devices and objects that are interconnected. From audio-visuals to smart houses, this creates a whole new perspective on normal day-to-day interactions with devices. The Internet of things (IoT) is made up of devices and objects that are connected and contains the ability to transfer data over a network without either demanding human-to-human or human-to-computer interaction. According to Buyya, Gubbi, Marusic and Palaniswami (2013) [1], it was coined in 1999 by a British technology pioneer, Kevin Ashton. Throughout the years, the term IoT became synonymous with modern technology, covering the likes of transportation, health care, utilities etc. IoT gives autonomy in obtaining data without the need for human intervention. This gives us the freedom to remotely check the connected devices without the need to interact with them.

According to Guillemin, Friess, Sundmacker and Woelffl (2010) [2], IoT ideally combines computer networks, Internet of Media and Services in developing an IT platform of seamless networks. Internet of Media (IoM) involves the use of multimedia applications. Internet of Services (IoS) involves delivering software-based components through global channels. IoT is connected within the cloud and not in a Local Area Network (LAN) thus, it needs large storage capacity with a continuous connection to the Internet.

IoT can be divided in three categories: Industry, Environment, and Society. In the Industry category, financial or commercial transactions are activities that consist within this group. In the Environment category, activities, such as safety, maintenance and development of natural resources, are within this domain. In the Society category, activities that are contained in this section involves development of societies and its people. These categories are strongly interrelated which enables the development of new applications and services.

\section{LITERATURE REVIEW}

IoT Based Smart Garbage and Waste Collection Bin is a journal article by Killedar, Navghane and Rohokale (2016) [3]. They interfaced a microcontroller-based system having IR wireless systems along with central system to a dustbin and they were able to show the current status of garbage in a web browser. Their project depended upon the Wi-Fi module which was essential to their project. Their aim was to reduce human resources and effort along with the enhancement of a smart city vision. They were able to identify when the dustbin was empty, half-full or full as well as being heavy. They concluded that the system reduces trips of garbage collection vehicle and reduces overall expenditure associated with the garbage collection.

IoT Based Waste Management for Smart City is a journal article by Parkash and Prabu (2016) [4]. They utilized an 8051 Microcontroller, IR Sensor, RF Module and an Intel Galileo Gen2 to create their garbage bin management while using a web browser to visualize the state of the bin. They were able detect the waste level, transmit the information wirelessly, real-time data transmission and access and avoiding dustbin overflow. to display a GUI which can be accessed at any point of concern. They concluded that they have successfully implemented a real-time waste management system which can be remotely accessed anywhere and anytime by the concerned person. This system indirectly reduces traffic in the city and avoid unnecessary garbage collection vehicle visit due to being scheduled and may result in overflowing. 
IoT based Waste Collection System using Infrared Sensors is a journal article by Aggarwal, Arora and Singh (2016) [5]. Their study also utilizes RFID technology in determining the level of the garbage inside a waste bin. By using IR sensors instead of ultrasonic sensors, it was noteworthy that it was cheaper and has a faster response rate which is essential to real-time monitoring. Using a Raspberry Pi2 development board and IR obstacle line sensor, they were able to produce a waste management system that was significantly cost efficient, reduces emission, vehicle wear and tear, noise pollutions and work hours from garbage collection.

SWACHHL An Effective Real Time Solid Waste Management System for Municipality is a journal article by Ghate and Kurundkar (2016) [6]. They utilized an ultrasonic senor, Zigbee, GSM and Atmega328 microcontroller to power their system. They were able to implement these devices was able to create a GUI using Matlab. Their research mainly tackled the delay in the performance of the GSM which he concluded that the delay in network increases linearly with increase load size. Their system assures the cleaning of dustbins soon when the waste level is at its maximum and reduces the trips of garbage collection vehicles which also reduces the expenses associated with waste collection.

Intelligent Solid Waste Bin Monitoring and Management System is a journal article by Arebey, Basri, Begum and Hannan (2010) [7]. Their system involved the use of RFID associated with intelligent systems. GPS and GIS were used to track vehicle position. Using these systems, they were able to monitor vehicle position through GIS, optimize route destination, lower fuel cost, reduce air pollution and vehicle unavailability. The proposed system would ensure the practical and perfect solid waste collection process.

Another waste management system was produced involving a Decision Support System (DSS). A journal article by Anagnostopoulos, Fedchenkov and Khoruzhnikov (2015) [8], DSS is a system that incorporates a model for data sharing between garbage collection vehicles in real time to provide an optimized dynamic route in waste collecting. Their system handles ineffective waste collection in inaccessible areas within the city. Along with surveillance cameras to capture and provide evidence in problematic areas, it assists technology that is currently in use for a high quality of service in waste collection specifically IoT components, RFID, sensors, cameras and actuators.

The performance of ultrasonic sensors and infrared sensors vary on the material it is being reflected upon. According to Adarsh, Bose, Kaleemuddin and Ramachandran (2016) [9], ultrasonic sensors perform well when they are sensing sponge, wood, plastic and tile as obstacles while infrared sensors perform well when sensing paper as an obstacle. In their study, they observed that combining the ultrasonic sensor and infrared sensor can both be used to detect obstacle types cardboard and rubber. They concluded that ultrasonic sensors perform well towards a good set of obstacle types while infrared sensors perform well under a specific type of material.

A study conducted by Abad, et al. (2013) [10] entitled "Automated Waste Sorter with Mobile Robot Waste Delivery System" focused on automating the sorting process of recyclables, namely: steel cans, aluminum cans, glass bottles and plastic bottles. It was observed in the Philippines that there is proper waste segregation being practiced but not that effective. As a result, there are still wastes not being collected that contribute to the escalation in the amount of wastes. With this problem in mind, the group developed an Automated Waste Sorter (AWS) and Mobile Robot Waste Deliver System (MRWDS) in order to minimize the wastes and have a proper waste segregation. A conveyor belt together with a sensor array was created in order to have a proper segregation. Through the sensor array, the type of waste that is passing through the conveyor belt can be easily identified. Additionally, a mobile robot was installed in order to collect and properly deliver the wastes in the dump. Overall, the system was able to collect delivery and sort the waste with an accuracy of at least $80 \%$.

\section{THEORETICAL CONSIDERATION}

The For the waste bin management monitoring and tracking system to be able to perform the objectives that is required, it must have modules for the waste level detection, database connectivity and mobile application. Those modules will serve as the vital roles in completing the system and its goal to monitor and track the waste level. The system will be made using the ADAFruit Feather Wi-Fi HUZZAH ESP8266 and the software android studio. The ADAFruit Feather Wi-Fi HUZZAH ESP8266 was used as the central processing unit of the system where it will receive the data gained from the sensors and push it to the server. The mobile application will then be created using android studio and fetch the data from server. By using an android phone [11,12], It will then present a graphical user interface of the waste level and detect whether the bin is ready to be collected or not.

Feather is the new development board from Adafruit, and like its namesake it is thin and light. We designed Feather to be a new standard for portable microcontroller cores. This is the Adafruit Feather HUZZAH ESP8266 Wi-Fi development board with built in USB and battery charging. It is an ESP8266 Wi-Fi module with all the extras you need. At the Feather HUZZAH's heart is an ESP8266 Wi-Fi microcontroller clocked at $80 \mathrm{MHz}$ and at $3.3 \mathrm{~V}$ logic. This microcontroller contains a Tensilica chip core as well as a full Wi-Fi stack. You can program the microcontroller using the Arduino IDE for an easy-to-run Internet of Things core. We wired up a high-quality SiLabs CP2104 USB-Serial chip that can upload code at a blistering 921600 baud for fast development time. It also has auto-reset so no noodling with pins and reset button pressings. The CP2104 has better driver 
support than the $\mathrm{CH} 340$ and can do very high speeds without stability issues.

Firebase Database is a NoSQL cloud database by Google. It is a mobile and web development platform. It serves a whole suite of service for developers such as real time database, analytics, notifications and more. In this thesis, the real time database will be implemented to fit with the real time adjustment of the prototype.

Using dual sensors increases the accuracy of the reading. The ultrasonic sensor can read most of the materials but lack in some areas. This is where the infrared sensor comes into play. It acts as a secondary sensor in order to accurately read the materials that are otherwise inaccurate for the ultrasonic sensor. Due to the limitations of the infrared sensor, the readings for this sensor are cut off by $10 \mathrm{~cm}$ and the final output value will be the ultrasonic sensor. Otherwise, the average of the sensors will be the final output value.

When using two sensors, there is always a more superior

\section{DESIGN CONSIDERATION}

The group made a waste bin management system with mobile monitoring and tracking by using a microprocessor as its base. 2 sensors are then placed at the detection module and pushed to the microprocessor. It then pushes the data to the server and the mobile application fetches the data from the server. The settings are just like in the study of [13]. Shown in Fig. 1 is the prototype block diagram.

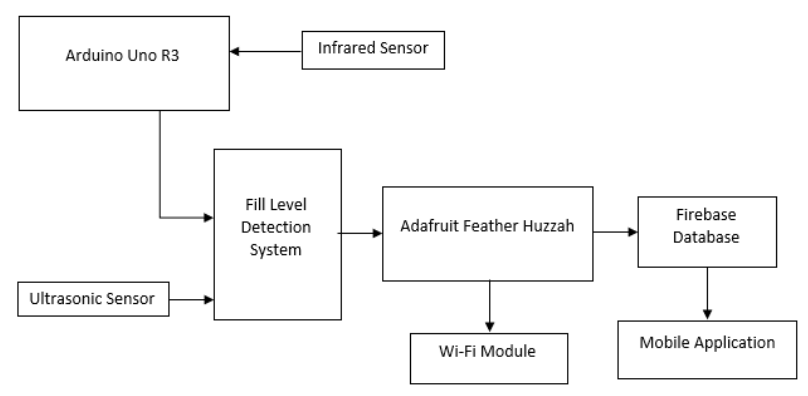

Figure 1: Prototype Block Diagram

This module has a powerful enough on-board processing and storage capability that allows it to be integrated with the sensors and other application specific devices through its GPIOs with minimal development up-front and minimal loading during runtime. Its high degree of on-chip integration allows for minimal external circuitry, including the front-end module, is designed to occupy minimal PCB area. The ESP8266 supports APSD for VoIP applications and Bluetooth co-existence interfaces; it contains a self-calibrated RF allowing it to work under all operating conditions and requires no external RF parts. These information are placed in a database, where the Rough Set Theory can be used to optimize it $[14,15,16,17]$. sensor compared to the other one. The ultrasonic sensor was able to read at 5 percent deviation to its expected readings while the infrared sensor was only able to accurately read from $10 \mathrm{~cm}$ to $40 \mathrm{~cm}$. It is good to note that the important range that we will be noting is above the $60 \mathrm{~cm}$ range which is around 60-90 percent of the GUI since this will indicate that whether the bin is ready to be collected or filled to the brim. By using the measurements from $83 \mathrm{~cm}$ to $40 \mathrm{~cm}$ and $10 \mathrm{~cm}$ to $1 \mathrm{~cm}$, we will be using the readings from the ultrasonic sensor while adding the readings from the infrared sensor and averaging it with the ultrasonic sensor to get an accurate reading as it reaches the distance from $40 \mathrm{~cm}$ to $10 \mathrm{~cm}$.

Android Studio provides the fastest tools for building apps on every type of Android device. World-class code editing, debugging, performance tooling, a flexible build system, and an instant build/deploy system all allow you to focus on building unique and high-quality apps. Robust and flexible build system easily configures your project to include code libraries and generate multiple build variants from a single This microcontroller contains 14 digital input/output pins, 6 analog inputs, and a $16 \mathrm{MHz}$ quartz crystal. This will be mainly used to power the infrared sensor in order for the researcher to utilize the sensor and push the data to the ESP8266. These data are placed in a database with various configurations like in the studies of: [18, 19, 20,21].

Ultrasonic sensors use electrical energy and a ceramic transducer to emit and receive mechanical energy in the form of sound waves. Sound waves are essentially pressure waves that travel through solids, liquids and gases and can be used in industrial applications to measure distance or detect the presence or absence of targets. The beam shape of the sensor is conical and the width of the beam is a function of the surface area, frequency and type of transducers used. The beam spread at maximum sensitivity is 38 inches across at 10 $\mathrm{ft}$. away from the sensor. The sensor can detect all types of obstacles such as metal, wood, concrete wall, plastic etc., with an extremely less affinity with the lighting conditions. The velocity of the ultrasonic wave travel in the air is usually affected by the parameters such as ambient noise, temperature, humidity.

Infrared (IR) technology addresses a broad variety of wireless applications, especially in the areas of sensing and remote control. Today's newest products, such as cell phones, digital cameras, and DVD players as well as remote controls for every market segment, rely on IR sensing and control devices. Using this sensor alongside the ultrasonic sensor, the group can remove the errors committed by the ultrasonic sensor thereby increasing the accuracy of the system. 


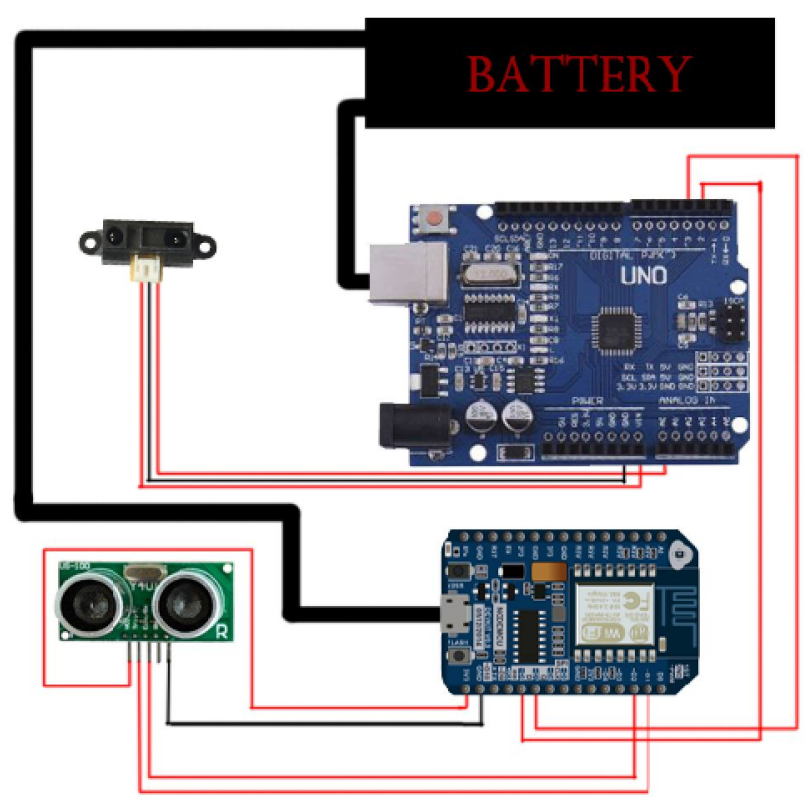

Figure 2: Prototype Schematic Diagram

Fig. 2 shows the schematic diagram of the system. The battery is connected to the voltage source of each microprocessor. The VCC, Trig, Echo and GND of the ultrasonic sensor was connected to $3 \mathrm{v} 3, \mathrm{D} 1, \mathrm{D} 2$ and GND, respectively, of the ESP8266. D7 and D8 pins of the ESP8266 were then connected to the digital pins 3 and 2, respectively, of the Arduino Uno R3. The Output pin, VCC and GND of the infrared sensor was connected to the A0, VIN and GND of the Arduino Uno R3, respectively.



Figure 3: Actual Prototype

The prototype is then placed underneath the lid of the waste bin as seen in Fig. 3. The prototype will then read anything it senses underneath the waste bin. The waste bin attached is a 60 -liter bin with dimensions of $330 \mathrm{~mm}$ in length, $330 \mathrm{~mm}$ in width and $889 \mathrm{~mm}$ in height. Shown in Fig. 4 is the actual bin being tested upon. An RFID transmitter can be used to send the information $[22,23,24,25]$.

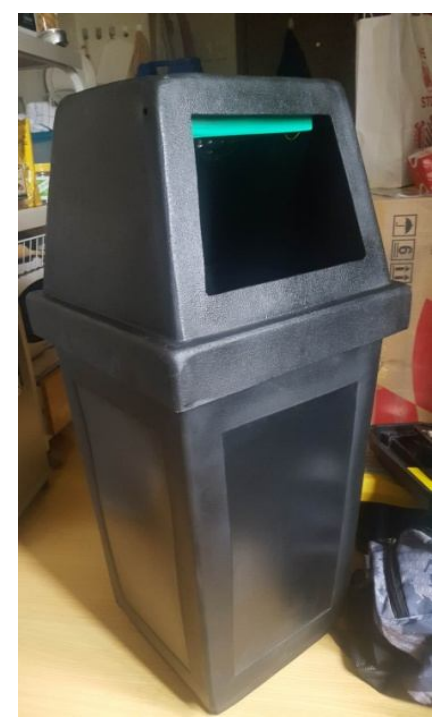

Figure 4: TC 60L NDS Waste Bin

\section{METHODOLOGY}

Fig. 5 shows the ESP8266 with its pin layout. Using the ultrasonic sensor, the group soldered the VCC, Trig, Echo and GND to its corresponding pins which are $3 \mathrm{v} 3, \mathrm{D} 1, \mathrm{D} 2$ and GND, respectively, to access the sensor and apply our created code using the Arduino IDE. Since the IR sensor needed a 5v connection, the group used pins D7 and D8 to connect to the Arduino Uno R3. Spatial Processing can be used to optimize it [26]. Another optimization method that can be used is Neural Networks [27].

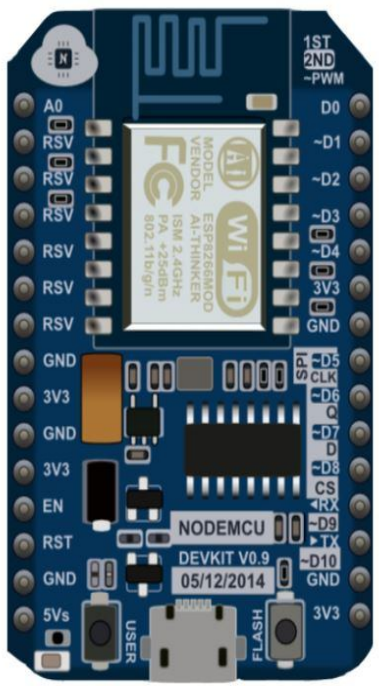

Figure 5: ESP8266 Pin Layout

Fig. 5 shows the Arduino Uno R3 with its pin layout. The group implemented the IR sensor code to the Arduino Uno R3 using the Arduino IDE and then connected the pins D7 and D8 of the ESP8266 module to the digital pins 2 and 3. After applying the code and connecting to the ESP8266, the group 
then edited the code that is being used by ESP8266 to implement both sensors.



Figure 6: Arduino Uno R3 Pin Layout

Using Google's Firebase Realtime Database, the group was able to send the data coming from the ESP8266 to the mobile application [28]. It is important to define the FIREBASE_HOST and FIREBASE_AUTH in calling the library from the Arduino IDE. Then to initiate it, the group use FIREBASE.begin(FIREBASE_HOST, FIREBASE_AUTH) to begin sending the data from the ESP8266 to the server. To connect the server to the mobile application, the group used this code FirebaseDatabase database = FirebaseDatabase.getInstance(); in our main java file to execute the connection between the server to the mobile application. Shown in Fig. 6 is the graphical user interface and mobile application Waste Bin Management System (WBMS).

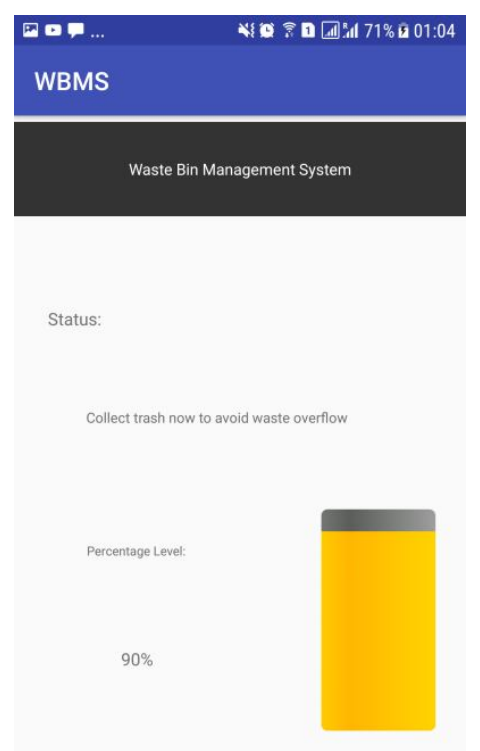

Figure 7: Graphical User Interface and WBMS Application

The location that was chosen is the waste bins located in Bro. Bloemen Hall in De La Salle University - Manila. The place was specifically chosen since it is the dining area of most students and is prone to overflowing. There are 3 locations of waste bins which indicate that the area was more likely to produce waste from students purchasing food in the stalls. The prototype was place underneath the lid of the waste bin and directly facing the waste. The location is shown in Fig. 7.

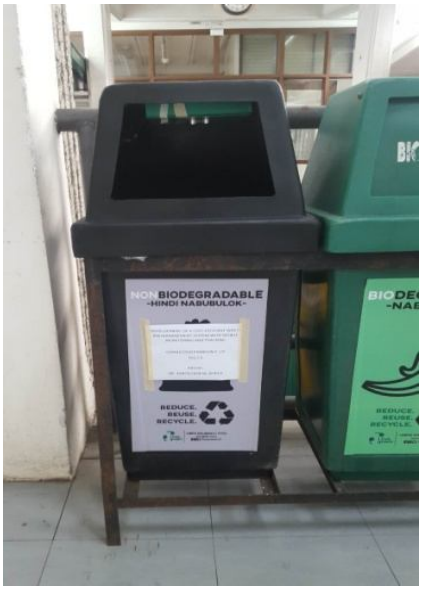

Figure 8: Prototype Location and Deployment

The expected output of the sensors is indicated from the Table 1. The group measured the waste bins of our chosen location and obtained a height of $90 \mathrm{~cm}$ including the lid of the waste bin. Once the lid was removed, the height is now $65 \mathrm{~cm}$. With this information, the group formulated the specific distances of each percentages. 10 levels of percentages were used with intervals of $9 \mathrm{~cm}$ as each level increases.

Table 1: Expected Output and Results

\begin{tabular}{|c|c|}
\hline Amount of Waste & Percentage \\
\hline$x<5 \mathrm{~cm}$ & 100 \\
\hline $5 \mathrm{~cm}<\mathrm{x}<9 \mathrm{~cm}$ & 90 \\
\hline $9 \mathrm{~cm}<\mathrm{x}<18 \mathrm{~cm}$ & 80 \\
\hline $18 \mathrm{~cm}<\mathrm{x}<27 \mathrm{~cm}$ & 70 \\
\hline $27 \mathrm{~cm}<x<36 \mathrm{~cm}$ & 60 \\
\hline $36 \mathrm{~cm}<x<45 \mathrm{~cm}$ & 50 \\
\hline $45 \mathrm{~cm}<x<54 \mathrm{~cm}$ & 40 \\
\hline $54 \mathrm{~cm}<x<63 \mathrm{~cm}$ & 30 \\
\hline $63 \mathrm{~cm}<x<72 \mathrm{~cm}$ & 20 \\
\hline $72 \mathrm{~cm}<x<81 \mathrm{~cm}$ & 10 \\
\hline $\mathrm{x}>81 \mathrm{~cm}$ & 0 \\
\hline
\end{tabular}


The group observed that the time slots, shown in Tale 2, were specifically made to cater to the time the students are attending their lectures and during their break time. An hour and 45 minutes interval were used by the group to serve as the correct time interval since class duration is expected to be an hour and 30 minutes while break time is 15 minutes.

Table 2: Time Table

\begin{tabular}{|c|}
\hline Time Slot \\
\hline $09: 00-10: 45$ \\
\hline $10: 45-12: 30$ \\
\hline $12: 30-14: 15$ \\
\hline $14: 15-16: 00$ \\
\hline $16: 00-17: 45$ \\
\hline $17: 45-18: 30$ \\
\hline
\end{tabular}

Overflow limit is accounted for once the waste bin reaches at least 75 percent. This does not mean that overflowing occurs, but it is now prone to overflow since there are moments that some students avoid placing waste once they see the level of waste starts to reach around 75 percent. The duration starts when the waste bin reaches 75 percent and ends when the maintenance staff has cleared or compressed the waste bin.

\section{RESULTS AND DISCUSSION}

When compared to the expected outcome, the results of the test run were not erroneous. The discrepancies between values never exceed 3 centimeters, and both would always fall within the same numerical range. Inaccuracies gradually become more evident when the distance to the trash increases, which is most likely due to the combined average of the two sensors. However, the accuracy of the 75-100 percent approximation is more crucial, since it is within this range that the overflow warning appears. This is where the maintenance staff would usually start being more attentive with the trash content of the bins. The observed outcome of the GUI remains accurate from 75-100 percent, as only one sensor is being used in this range.

Table 3: Experiment Output and Results

\begin{tabular}{|c|c|}
\hline Amount of Waste & Percentage \\
\hline $\mathrm{x}<6 \mathrm{~cm}$ & 100 \\
\hline
\end{tabular}

\begin{tabular}{|c|c|}
\hline $6 \mathrm{~cm}<x<9 \mathrm{~cm}$ & 90 \\
\hline $9 \mathrm{~cm}<\mathrm{x}<19 \mathrm{~cm}$ & 80 \\
\hline $19 \mathrm{~cm}<\mathrm{x}<28 \mathrm{~cm}$ & 70 \\
\hline $28 \mathrm{~cm}<\mathrm{x}<39 \mathrm{~cm}$ & 60 \\
\hline $39 \mathrm{~cm}<\mathrm{x}<47 \mathrm{~cm}$ & 50 \\
\hline $47 \mathrm{~cm}<\mathrm{x}<54 \mathrm{~cm}$ & 40 \\
\hline $54 \mathrm{~cm}<x<65 \mathrm{~cm}$ & 30 \\
\hline $65 \mathrm{~cm}<x<73 \mathrm{~cm}$ & 20 \\
\hline $73 \mathrm{~cm}<x<82 \mathrm{~cm}$ & 10 \\
\hline$x>82 \mathrm{~cm}$ & 0 \\
\hline
\end{tabular}

The device consistently sent overflow warnings throughout the day. As seen in Fig. 7, it is common to see uncompressed waste. The maintenance staff often compresses the trash to fit more waste. Even when overflowing was occurring frequently during peak time, there were neither malfunctions nor errors coming from the device. If there was a reliable internet connection, WBMS was able to be monitored through the app. The only issue presented itself when the internet connection was unstable, in which the warnings would not get through. Another method that can be used is Machine Vision win Big Data Analysis [29,30,31,32].

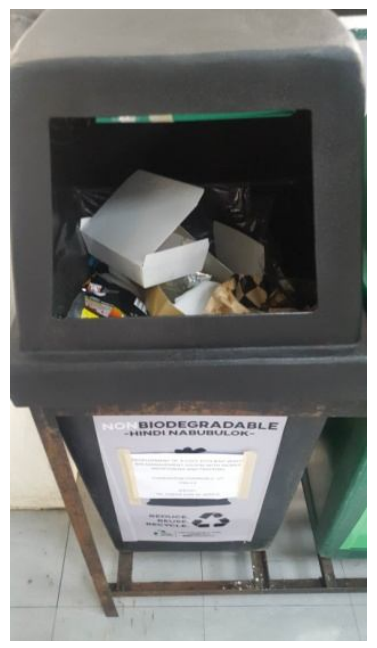

Figure 9: Prototype with Waste at 75 Percent 
Table 4 shows the number of times 75 percent was reached. Each time the application reaches at this point, it is documented to an excel sheet manually when observing.

Table 4: Time Table with Overflow Occurrence

\begin{tabular}{|c|c|}
\hline Time Slot & $\begin{array}{c}\text { Number of Times 75 Percent } \\
\text { and Above was Read }\end{array}$ \\
\hline $09: 00-10: 45$ & 1 \\
\hline $10: 45-12: 30$ & 2 \\
\hline $12: 30-14: 15$ & 3 \\
\hline $14: 15-16: 00$ & 3 \\
\hline $16: 00-17: 45$ & 2 \\
\hline $17: 45-18: 30$ & \\
\hline
\end{tabular}

The maintenance staff was able to take advantage of the notifications they were receiving from the device. The 75 percent and above warnings gave them notice that the bins are close to overflowing and helped them gage how much time they have before it reaches that point. Shown in Table 5 are the results of the experiment. There were only difficulties and slight delays with peak time, since there were more bins to manage than usual, which leaves some bins unmanaged for a slightly longer period.

Table 5: Duration of Overflow with WBMS and without WBMS

\begin{tabular}{|c|c|c|}
\hline Time Slot & Without WBMS & With WBMS \\
\hline $09: 00-10: 45$ & 3 minutes & 1 minute \\
\hline $10: 45-12: 30$ & 5 minutes & 1 minute \\
\hline $12: 30-14: 15$ & 7 minutes & 2 minutes \\
\hline $14: 15-16: 00$ & 5 minutes & 3 minutes \\
\hline $16: 00-17: 45$ & 4 minutes & 2 minutes \\
\hline $17: 45-18: 30$ & 4 minutes & 1 minute \\
\hline
\end{tabular}

The test runs of the WBMS provided the maintenance staff with a reliable avenue for the monitoring of trash overflow. The accuracy of the GUI was as constant as expected, and overflow warnings were consistent even during peak time. The warnings helped ease the trash overflow faster, since the maintenance staff is alerted about the trash sooner. Trouble would only arise if the internet connection is unstable, since the overflow warnings would not come through, and if maintenance is undermanned.

\section{CONCLUSION}

The objective of the thesis is to create a cost-efficient waste bin management system with mobile monitoring and tracking. The researcher has achieved to make a monitoring system with a mobile application. The WBMS application proved to be useful regarding informing the maintenance staff when to start collecting the waste. Being cost-efficient since the prototype only costs $\mathrm{Php} 1627.00$, it is possible to create a cost-efficient waste bin management system. The GUI was also helpful in presenting the data to the end-user since a significant amount of time was reduced when it was time to collect. By using a mobile application, the researcher was able to present the maintenance staff an application that is catered to their needs. Since implementing the WBMS, the maintenance staff was alerted whenever the waste bin reached a certain point where overflow may happen thus reduced the amount of time it took for the maintenance staff to collect the waste.

The ESP8266 is the main component that acts as the transport of data from the sensors to the server. The limitation of this is the $5 \mathrm{~V}$ pin that was unavailable. Therefore, to reduce the use of another microcontroller, the group recommends finding a microprocessor that is inexpensive, able to transmit data via Wi-Fi and contain all the necessary pin connections for the sensors. Finally, adding an "add device" could lead the way to connecting more waste bins and ease of use for maintenance staff.

\section{REFERENCES}

[1] J. Gubbi, R. Buyya, S. Marusic, and M. Palaniswami, "Internet of things (iot): A vision, architectural elements, and future directions," Future Generation Computer Systems. Vol. 29, No.7, pp. 1645-1600, 2013. https://doi.org/10.1016/j.future.2013.01.010

[2] H. Sundmaeker, P. Guillemin, P. Friess, and S. Woelffl'e, "Vision and Challenges for Realising the Internet of Things," Luxembourg: Publications Office of the European Union. 2010.

[3] S. Navghane, M. Killedar, and V. Rohokale, "Iot based smart garbage and waste collection bin," International Journal of Advanced Research in Electronics and Communication Engineering (IJARECE). Vol. 5, p. 1576 - 1578, 2016. 
[4] T. Parkash and V. Prabu, "Iot based waste management for smart city," International Journal of Innovative Research in Computer and Communication Engineering. Vol. 4, p. 1267 - 1274, 2016.

[5] A. Singh, P. Aggarwal, and R. Arora, "Iot based waste collection system using infrared sensors," 5th International Conference on Reliability, Infocom Technologies and Optimization (Trends and Future Directions) (ICRITO). pp. 505-509, 2016. https://doi.org/10.1109/ICRITO.2016.7785008

[6] S. S. Ghate and S. V. Kurundkar, "Swachh: An effective real time solid waste management system for municipality," International Journal of Computer Applications. Vol. 149, pp. 44-48, 2016. https://doi.org/10.5120/ijca2016911393

[7] M. Hannan, M. Arebey, H. Basri, and R. Begum, "Intelligent solid waste bin monitoring and management system," Australian Journal of Basic and Applied Sciences. Vol. 4, No. 10, pp. 5314-5319, 2010.

[8] A. Medvedev, P. Fedchenkov, A. Zaslavsky, T. Anagnostopoulos, and S. Khoruzhnikov, "Waste Management as an IoT-Enabled Service in Smart Cities," Cham: Springer International Publishing. pp. 104-115, 2015 . https://doi.org/10.1007/978-3-319-23126-6_10

[9] S. Adarsh, S. M. Kaleemuddin, D. Bose, and K. I. Ramachandran, "Performance comparison of infrared and ultrasonic sensors for obstacles of different materials in vehicle/ robot navigation applications," IOP Conference Series: Materials Science and Engineering. Vol. 149, No. 1, pp. 012141, 2016. https://doi.org/10.1088/1757-899X/149/1/012141

[10] A. Abad, F. Ang, A. Gabriel, J. Sy and J. Tan "Automated waste sorter with mobile robot waste delivery system." De La Salle University Research Congress. 2013.

[11] A. Africa and J. Velasco, "Development of a Urine Strip Analyzer using Artificial Neural Network using an Android Phone." ARPN Journal of Engineering and Applied Sciences. Vol. 12, No. 6, pp. 1706-1712, 2017.

[12] A. Africa, A. Mesina, J. Izon, and B. Quitevis, "Development of a Novel Android Controlled USB File Transfer Hub." Journal of Telecommunication, Electronic and Computer Engineering. Vol. 9, Nos. 2-8, pp. 1-5, 2017.

[13] A. Africa, A. Chua, S. Chua, J. Gregorio, and M. Quilnet, "Two-way SMS and braille communication for the visually impaired." ARPN Journal of Engineering and Applied Sciences. Vol. 14, No. 2, pp. 425-432, 2019.

[14] A. Africa, "A Rough Set-Based Expert System for diagnosing information system communication networks." International Journal of Information and Communication Technology. Vol. 11, No. 4, pp. 496-512, 2017. https://doi.org/10.1504/IJICT.2017.10008315

[15] A. Africa and M. Cabatuan, "A Rough Set Based Data Model for Breast Cancer Mammographic Mass Diagnostics." International Journal of Biomedical
Engineering and Technology. Vol. 18, No. 4, pp.359-369, 2015.

https://doi.org/10.1504/IJBET.2015.071010

[16] A. Africa, "A Rough Set Based Solar Powered Flood Water Purification System with a Fuzzy Logic Model." ARPN Journal of Engineering and Applied Sciences. Vol. 12, No. 3, pp.638-647, 2017.

[17] A. Africa, "A Mathematical Fuzzy Logic Control Systems Model Using Rough Set Theory for Robot Applications." Journal of Telecommunication, Electronic and Computer Engineering. Vol. 9, No. 2-8, pp. 7-11, 2017.

[18] A. Africa and M. Ladrido, "Comparative Study of Intrusion Detection Systems against Mainstream Network Sniffing Tools." International Journal of Engineering \& Technology. Vol. 7, Nos, 4.16, pp. 188-191, 2018.

[19] A. Africa and L. Torrizo, " Comparative Study of Intrusion Detection Systems against Mainstream Network Sniffing Tools." International Journal of Engineering \& Technology. Vol. 7, Nos. 4.16, pp.188-191, 2018.

[20] A. Africa, "A Logic Scoring of Preference Algorithm using ISO/IEC 25010:2011 for Open Source Web Applications Moodle and Wordpress." ARPN Journal of Engineering and Applied Sciences. Vol. 13, No.15, 2018.

[21] S. Brucal, A. Africa, and E. Dadios, "Female Voice Recognition using Artificial Neural Networks and MATLAB Voicebox Toolbox." Journal of Telecommunication, Electronic and Computer Engineering. Vol. 10, Nos. 1-4, pp. 133-138, 2018.

[22] A. Africa, S. Bautista, F. Lardizabal, J. Patron, and A. Santos, "Minimizing Passenger Congestion in Train Stations through Radio Frequency Identification (RFID) coupled with Database Monitoring System." ARPN Journal of Engineering and Applied Sciences. Vol. 12, No. 9, pp. 2863-2869, 2017.

[23] A. Africa and M. Ladrido, M, "Comparative Study of Intrusion Detection Systems against Mainstream Network Sniffing Tools." International Journal of Engineering \& Technology. Vol. 7, Nos. 4.16, pp. 188-191, 2018.

[24] A. Africa and L. Torrizo, "Comparative Study of Intrusion Detection Systems against Mainstream Network Sniffing Tools." International Journal of Engineering \& Technology. Vol. 7, Nos. 4.16, pp. 188-191, 2018.

[25] A. Africa, A. Chua, S. Chua, J. Gregorio, and M. Quilnet, "Two-way SMS and braille communication for the visually impaired." ARPN Journal of Engineering and Applied Sciences. Vol.14, No. 2, pp.425-432, 2019.

[26] P. Loresco and A. Africa, "ECG Print-out Features Extraction Using Spatial-Oriented Image Processing Techniques." Journal of Telecommunication, Electronic and Computer Engineering. Vol. 10, Nos. 1-5, pp. 15-20, 2018.

[27] L. Villanueva, and R.C. Gustilo, "Artificial neural network based antenna sensitivity assignments for chaotic Internet Service Provider network architecture." 
International Journal of Engineering and Technology

(UAE). Vol. 7, No. 2, pp. 14-17, 2018

https://doi.org/10.14419/ijet.v7i2.3.9958

[28] A. Africa, J. Aguilar, C. Lim Jr, P. Pacheco, and S. Rodrin, "Automated Aquaculture System that Regulates $\mathrm{Ph}$, Temperature and Ammonia." 9th International Conference on Humanoid, Nanotechnology, Information Technology, Communication and Control, Environment, and Management (HNICEM). 2017.

https://doi.org/10.1109/HNICEM.2017.8269494

[29] R.C. Gustilo, and E. Dadios, "Machine vision support system for monitoring water quality in a small scale tiger prawn aquaculture." Journal of Advanced Computational Intelligence and Intelligent Informatics. Vol. 20, No. 1, pp. 111-116, 2016. https://doi.org/10.20965/jaciii.2016.p0111

[30] R.C. Gustilo, and E. Dadios, "Behavioural response analysis using vision engineering (BRAVENet)." Journal of Advanced Computational Intelligence and Intelligent Informatics. Vol. 21, No. 2, pp. 211-220, 2017. https://doi.org/10.20965/jaciii.2017.p0211

[31] D. Ahamad, M. Akhtar, and S. Hameed, "A Review and Analysis of Big Data and MapReduce." International Journal of Advanced Trends in Computer Science and Engineering ( IJATCSE ). Vol. 8, No. 1, pp. 1-3, 2019. https://doi.org/10.30534/ijatcse/2019/01812019

[32] M. Tawarish, and K. Satyanarayana, "A Review on Pricing Prediction on Stock Market by Different Techniques in the Field of Data Mining and Genetic Algorithm." International Journal of Advanced Trends in Computer Science and Engineering ( IJATCSE ). Vol. 8, No. 1, pp. 23-26, 2019.

https://doi.org/10.30534/ijatcse/2019/05812019 